\title{
Hybrid Behavioral-Analytical Loss Model for a High Frequency and Low Load DC-DC Buck Converter
}

\author{
D. Díaz, M. Vasić, O. García, J.A. Oliver, P. Alou, J.A. Cobos \\ Universidad Politécnica de Madrid \\ Centro de Electrónica Industrial \\ José Gutiérrez Abascal 2, 28006 Madrid
}

\begin{abstract}
This work presents a behavioral-analytical hybrid loss model for a buck converter. The model has been designed for a wide operating frequency range up to $4 \mathrm{MHz}$ and a low power range (below 20W). It is focused on the switching losses obtained in the power MOSFETs. Main advantages of the model are the fast calculation time (below 8.5 seconds) and a good accuracy, which makes this model suitable for the optimization process of the losses in the design of a converter. It has been validated by simulation and experimentally with one GaN power transistor and three Si MOSFETs. Results show good agreement between measurements and the model.
\end{abstract}

\section{INTRODUCTION}

One of the most useful tools in the design and optimization of a converter is a power losses model. It can be used to select the best architecture for a set of specifications or to choose the best devices at the topology level to optimize the efficiency of the converter. In the literature, several types of model can be identified:

- Analytical model $[1,2,3,4,5,6]$

- Behavioral model $[7,8]$

- Physics model $[9,10]$

A physics based model has the advantages of a high level of detail, but the disadvantages of a long time of computation, even with a high performance computer. The behavioral model is balanced in terms of accuracy and computation time, but can have accuracy problems if the static and dynamic nonlinear effects are not considered. Finally, the analytical model relies on equations that take into account the non-idealities of the converter, and provides a faster simulation. Despite being a faster method compared to the other ones, its accuracy is the weakest point.

In this work a hybrid implementation between a behavioral and an analytical loss model is presented. The objective is to combine the advantages of both of them to manage a good trade-off between accuracy in the efficiency and losses estimation and a low computation time to be used as an optimization tol in the design of a converter or architecture at higher design level. The model has been focused for a low power range (below 20W) and high frequency (up to $4 \mathrm{MHz}$ ) buck converter, where switching losses are dominant. Main advantages are: firstly a good accuracy, even for low load operating conditions and for a wide frequency range (up to $4 \mathrm{MHz}$ ). The low computation time achieved, that will be quantified later, is very important for the optimization process in the design of a converter or architecture. The model can be easily applied to any MOSFET whose main datasheet parameters are known. Additionally, due to the behavioral characteristic of the model, the calculation of the main waveforms of the switching transition is done, allowing a validation using any of the time domain simulators available in the market. For this work, it has been used PSpice to compare the obtained waveforms in the switching transitions with the simulations.

Despite it has not been designed for a particular application, due to the high switching frequency and low power range, one of the most suitable one is the design and optimization of the envelope amplifier to supply the high efficiency radiofrequency power amplifier for EER technique. This application demands a high efficiency power supply for a wide range of frequencies, and with a highly variable load. The power and switching frequency requirements can fit applications as the radiofrequency power amplifier for microsatellites or for medium bandwidth communication services as satellite telephony or trunked radio systems. Experimental results are provided considering these specifications, detailed in section IV.

\section{DeSIGN OF THE BuCK Loss ModeL}

The presented model is based on a simplified synchronous buck converter and has been mainly focused on the MOSFETs losses (power losses in magnetic components and capacitors haven't been modeled in this work). Figure 1 shows the schematic circuit of the synchronous buck converter. Due to the high frequency operation, the parasitic inductances of the MOSFET $\left(\mathrm{L}_{\mathrm{d}}, \mathrm{L}_{\mathrm{s}}, \mathrm{L}_{\mathrm{g}}\right)$ and also the parasitic inductance of the PCB, $\mathrm{L}_{\mathrm{pcb}}$, are considered.

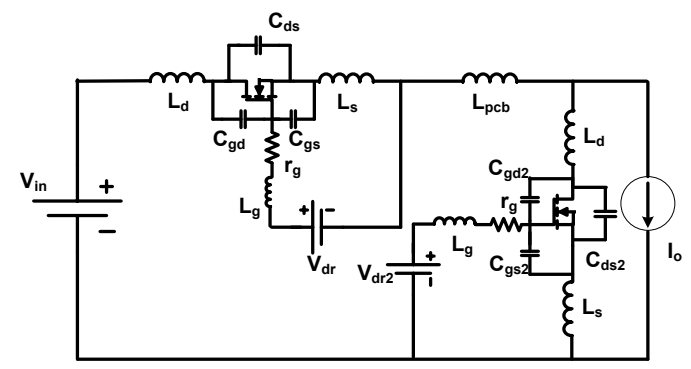

Figure 1. Schematic circuit of the modeled synchronous buck converter 
Main assumptions of the model are the load behavior as a current source and that the inductor used in experiments has been designed to obtain a DC output current in the operating range to decouple the core losses and the wire AC losses from the converter losses.

Analytical expressions to model the nonlinear parasitic capacitances and the forward transconductance have been considered. The parasitic capacitances are obtained using the equation (1) to fit the datasheet curves, where $C_{p}\left(C_{d s}, C_{g s}\right.$ or $\left.C_{g d}\right)$ depends on the $V_{d s}$ and on three constant parameters:

$$
C_{\mathrm{p}}=\left(\mathrm{V}_{\mathrm{ds}}(\mathrm{t})+\mathrm{k}_{1}\right)^{\mathrm{k}_{2} \cdot \mathrm{k}_{3}}
$$

The equation model of the transconductance is based on the same equation type. The three constant parameters are calculated to fit accurately the datasheet curves. In case this equation has not fitted properly the datasheet curve, a piecewise-polynomial function has been used, to ensure in all cases a good fitting of the curves. This method for modeling the capacitances is important because allows the use of the model for different types of power transistors, as $\mathrm{GaN}$, with a different shape for the curve of the parasitic capacitances as a function of the drain-source voltage, compared to Si MOSFETs.

Additionally, the following parameters are considered for the model: $\mathrm{V}_{\mathrm{dr}}$ and $\mathrm{V}_{\mathrm{dr} 2}$ (drivers input voltages), $\mathrm{V}_{\mathrm{d}}$ (body diode forward voltage), $\mathrm{Q}_{\mathrm{g}}, \mathrm{Q}_{\mathrm{rr}}, \mathrm{V}_{\text {th }}$, $\underline{\mathrm{R}}_{\mathrm{DSon} 2}$ dead times between control signals, $\mathrm{R}_{\mathrm{g}}$ and inductor $R_{d c}$. All these parameters have been also obtained from the datasheet. However, measurements of parasitic capacitances, transconductance at different $\mathrm{V}_{\mathrm{gs}}$ voltages, $\mathrm{R}_{\mathrm{DSon}}$ have been done to increase the accuracy of the analytical expressions and to check the accuracy of the datasheet parameters.

As it can be deduced from Figure 1, it is very complex to obtain the equation that describes the converter in a closed form, especially when it is necessary to model non-linear capacitors and variable transconductance. These parameters have strong influence on the efficiency estimation and if they are modeled with constant values it can lead to huge error in the estimation. Therefore, a different approach has been used:

- Obtention of the equivalent circuit for each sub-period of the transition.

- Calculation of the differential equations of the state variables for each period.

- Iterative numerical calculation of the state variables evolution with a fixed time step (1ps).

- At the end of the transition all the losses are obtained. After the last step of a switching transition, the energy stored in the parasitic components is discharged and therefore, taken into account as part of the losses.

The proposed model is based on two main transition periods (high side turn-on and high side turn-off) that are modeled independently. Starting from the steady state conditions at the beginning of the transitions, the main waveforms and the losses can be obtained. The main intervals are based on [5], but the implementation of the equations, the converter model, the parameters that are considered and the analytical curves obtained has been done under a different approach. Each switching transition is divided into several sub-periods, each one corresponding to a different equivalent circuit whose differential equations are calculated. The transitions between them are based on the values of the state variables as shown below, using the final values in a sub-period as the initial values for the next sub-period.

\section{1.-High side MOSFET turn-on:}

$\left.\underline{1.1-\left(\mathrm{V}_{\mathrm{gs}}\right.} \leq \mathrm{V}_{\underline{\mathrm{t}}}\right)$ : The turn on interval starts with the high side MOSFET off and with the driver voltage $\mathrm{V}_{\mathrm{dr}}$ applied, so $\mathrm{V}_{\mathrm{gs}}$ starts to increase. The behavior of the transistor is an open circuit for this interval, which ends when $\mathrm{V}_{\mathrm{gs}}$ reaches the threshold voltage of the MOSFET. The differential equations of the state variables in this period are the following:

$$
\begin{aligned}
& \frac{d i_{\mathrm{d}}}{\mathrm{dt}}=\frac{\mathrm{V}_{\mathrm{in}}+\mathrm{V}_{\mathrm{d}}-\mathrm{V}_{\mathrm{ds}}(\mathrm{t})+\mathrm{L}_{\mathrm{s}} \cdot\left(\frac{\mathrm{V}_{\mathrm{gs}}(\mathrm{t})+\mathrm{Rg}_{\mathrm{g}} \cdot \mathrm{i}_{\mathrm{g}}(\mathrm{t})-\mathrm{V}_{\mathrm{dr}}}{\mathrm{Lg}_{\mathrm{L}}+\mathrm{L}_{\mathrm{s}}}\right)}{\left(\mathrm{L}_{\mathrm{d}}+\mathrm{L}_{\mathrm{pcb}}+\mathrm{L}_{\mathrm{d}}+\mathrm{L}_{\mathrm{s}}+\frac{\mathrm{Lg} \cdot \mathrm{L}_{\mathrm{s}}}{\mathrm{Lg}+\mathrm{L}_{\mathrm{s}}}\right)} \\
& \frac{d i_{\mathrm{s}}}{\mathrm{dt}}= \\
& \frac{\left(\mathrm{V}_{\mathrm{dr}}-\mathrm{R}_{\mathrm{g}} \cdot \mathrm{i}_{\mathrm{g}}(\mathrm{t})-\mathrm{V}_{\mathrm{gs}}(\mathrm{t})\right) \cdot\left(\mathrm{L}_{\mathrm{d}}+\mathrm{L}_{\mathrm{pcb}}+\mathrm{L}_{\mathrm{d}}+\mathrm{L}_{\mathrm{s}}\right)+\mathrm{L}_{\mathrm{g}} \cdot\left(\mathrm{V}_{\mathrm{in}}+\mathrm{V}_{\mathrm{d}}-\mathrm{V}_{\mathrm{ds}}(\mathrm{t})\right)}{\left.\mathrm{L}_{\mathrm{s}} \cdot \mathrm{L}_{\mathrm{g}}+\left(\mathrm{L}_{\mathrm{d}}+\mathrm{L}_{\mathrm{pcb}}+\mathrm{L}_{\mathrm{s}}+\mathrm{L}_{\mathrm{d}}\right) \cdot\left(\mathrm{L}_{\mathrm{s}}+\mathrm{L}_{\mathrm{g}}\right)\right)}
\end{aligned}
$$

$$
\begin{aligned}
& \frac{d V_{\mathrm{ds}}}{\mathrm{dt}}=\frac{\frac{\mathrm{i}_{\mathrm{d}}(\mathrm{t})+\mathrm{i}_{\mathrm{g}}(\mathrm{t})}{\mathrm{C}_{g s}}+\frac{\mathrm{i}_{\mathrm{d}}(\mathrm{t})}{\mathrm{C}_{\mathrm{gd}}}}{1+\frac{\mathrm{C}_{\mathrm{ds}}}{\mathrm{C}_{\mathrm{gd}}}+\frac{\mathrm{C}_{\mathrm{ds}}}{\mathrm{C}_{\mathrm{gs}}}} \\
& \frac{d V_{\mathrm{gs}}}{\mathrm{dt}}=\frac{\frac{\mathrm{i}_{\mathrm{d}}(\mathrm{t})+\mathrm{i}_{\mathrm{g}}(\mathrm{t})}{\mathrm{C}_{\mathrm{ds}}}-\frac{\mathrm{i}_{\mathrm{d}}(\mathrm{t})}{\mathrm{C}_{\mathrm{ds}}+\mathrm{C}_{\mathrm{gd}}}}{\frac{\mathrm{C}_{g s}}{\mathrm{C}_{\mathrm{ds}}}+\frac{\mathrm{C}_{\mathrm{gd}}}{\mathrm{C}_{\mathrm{ds}}+\mathrm{C}_{\mathrm{gd}}}}
\end{aligned}
$$

The equations of the other state variables of the simplified buck converter shown in Figure $1\left(\mathrm{i}_{\mathrm{g}}\right.$ and $\left.\mathrm{V}_{\mathrm{gd}}\right)$ are obtained from equations (2) to (5). These values are added to the state variables values of the previous period in an iterative process.

1.2- $\left(\mathrm{V}_{\underline{\mathrm{ds}}}(\mathrm{t})>\mathrm{R}_{\underline{D S o n}} \cdot \underline{\mathrm{I}}_{0}\right) \&\left(\mathrm{I}_{\mathrm{d}}<\mathrm{I}_{0}\right)$ : The second stage starts when $\mathrm{V}_{\mathrm{gs}}>\mathrm{V}_{\text {th }}$ and lasts until $\mathrm{i}_{\mathrm{d}}$ or $\mathrm{V}_{\mathrm{ds}}$ reach their final values. As a simplification, it is used $I_{o}$ instead $\mathrm{I}_{\mathrm{o}}-\left(\Delta \mathrm{I}_{\mathrm{o}} / 2\right)$ due to the design of the inductor so the current has only DC component, as considered in the model assumptions. For this interval, the transistor is modeled by a current source whose value is obtained from the transconductance analytical equation calculated using the datasheet curves. 
Equations (2) and (3) are valid for this subinterval. However, the equations for the voltages change:

$\frac{d V_{\mathrm{ds}}}{\mathrm{dt}}=\frac{\frac{\mathrm{i}_{\mathrm{d}}(\mathrm{t})-\mathrm{i}_{\text {source }}+\mathrm{i}_{\mathrm{g}}(\mathrm{t})}{\mathrm{C}_{\mathrm{gs}}}+\frac{\mathrm{i}_{\mathrm{d}}(\mathrm{t})-\mathrm{i}_{\text {source }}}{\mathrm{C}_{\mathrm{gd}}}}{1+\frac{\mathrm{C}_{\mathrm{ds}}}{\mathrm{C}_{\mathrm{gd}}}+\frac{\mathrm{C}_{\mathrm{ds}}}{\mathrm{C}_{\mathrm{gs}}}}$

$$
\frac{d V_{g s}}{d t}=\frac{\frac{i_{d}(t)-i_{\text {source }}+i_{g}(t)}{C_{d s}}-\frac{i_{d}(t)-i_{\text {source }}}{C_{d s}+C_{g d}}}{\frac{C_{g s}}{C_{d s}}+\frac{C_{g d}}{C_{d s}+C_{g d}}}
$$

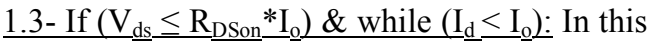
third sub-period, the transistor is modeled by the onresistance of the datasheet. If the current reaches faster the steady state value than the drain-source voltage, the model skips this stage and the analysis goes to the final sub-period.

In this sub-period, only the voltages equations are modified, substituting $i_{\text {source }}$ from (6) and (7) for $\mathrm{V}_{\mathrm{ds}}(\mathrm{t}) / \mathrm{r}_{\mathrm{on}}$

1.4- In the final part of this transition it is considered, for the parasitic inductances and the capacitances, the discharge of the remaining energy until the steady state is reached, and in this process the losses are produced by ringing. It is assumed that, in the range of operation considered, the parasitic components are totally discharged and the steady state is reached both in $\mathrm{t}_{\text {on }}$ and $\mathrm{t}_{\text {off }}$ intervals.

1.5- A partial calculation of the losses in this transition is done at this moment and stored to be used at the end of the calculations. Losses in this period are produced by:

- Driver and gate losses

- Body diode conduction

- Reverse recovery

- Ringing loss due to the energy stored in the parasitic components of the high side MOSFET

- Switching losses

Additionally, the conduction losses are added. An advantage of the implementation method for calculating the losses is that for the parasitic capacitance $\mathrm{C}_{\text {oss }}$ discharge (in case the voltage is slower than the current), at the end of the transient, it can be updated the value of the capacitance each step as the $V_{d s}$ is decreasing, which has a high impact in the value of this partial losses. In the ringing losses calculation it is considered that the ringing is finished before of the transition ends so all the energy stored in the parasitic components is lost.

2.-High side turn-off: Initially, the $\mathrm{V}_{\mathrm{dr}}$ of the high side MOSFET is turned to cero and the $\mathrm{V}_{\mathrm{gs}}(\mathrm{t})$ starts to decrease. During this transient, the low side MOSFET is considered to behave as an open circuit. Parasitic inductances are considered the same for both MOSFETs.

2.1- $\left(\mathrm{i}_{\mathrm{d}}<\mathrm{i}_{\text {source }}=\mathrm{f}\left(\mathrm{V}_{\mathrm{gs}}\right)\right)$ : The HS side transistor is modeled by the on resistance. The differential equations of the state variables in this interval are the following:

$$
\begin{aligned}
& \frac{d i_{\mathrm{d}}}{\mathrm{dt}}=\frac{\mathrm{A}(\mathrm{t})+\mathrm{B}(\mathrm{t})}{\mathrm{C}} \\
& \mathrm{A}(\mathrm{t})=\mathrm{V}_{\mathrm{in}}-\mathrm{V}_{\mathrm{ds}}(\mathrm{t})-\mathrm{V}_{\mathrm{ds} 2}(\mathrm{t}) \\
& \mathrm{B}(\mathrm{t})=\left(\frac{\mathrm{V}_{\mathrm{gs}}(\mathrm{t})+\mathrm{R}_{\mathrm{g}} \cdot \mathrm{i}_{\mathrm{g}}(\mathrm{t})+\mathrm{V}_{\mathrm{gs} 2}(\mathrm{t})+\mathrm{R}_{\mathrm{g} 2} \cdot \mathrm{i}_{\mathrm{g} 2}(\mathrm{t})}{\mathrm{L}_{\mathrm{g}}+\mathrm{L}_{\mathrm{s}}}\right) \cdot \mathrm{L}_{\mathrm{s}}
\end{aligned}
$$

$$
\mathrm{C}=2 \cdot \mathrm{L}_{\mathrm{d}}+\mathrm{L}_{\mathrm{pcb}}+2 \cdot \mathrm{L}_{\mathrm{s}} \cdot \frac{\mathrm{Lg}_{\mathrm{g}}}{\mathrm{Lg}_{\mathrm{g}}+\mathrm{L}_{\mathrm{s}}}
$$

$\frac{d i_{s}}{d t}=-\frac{\left(\mathrm{V}_{g s}(t)+R_{g} \cdot i_{g}(t)-\left[\frac{d i_{d}}{d t}\right] \cdot L_{g}\right)}{L_{s}+L_{g}}$

$\frac{d i_{\mathrm{s} 2}}{\mathrm{dt}}=-\frac{\left(\mathrm{v}_{\mathrm{gs} 2}(\mathrm{t})+\mathrm{R}_{\mathrm{g} 2} \cdot \mathrm{i}_{\mathrm{g} 2}(\mathrm{t})-\left[\frac{d i_{\mathrm{d}}}{\mathrm{dt}}\right] \cdot \mathrm{L}_{\mathrm{g}}\right)}{\mathrm{L}_{\mathrm{s}}+\mathrm{L}_{\mathrm{g}}}$

$\frac{d V_{\mathrm{ds}}}{\mathrm{dt}}=\frac{\frac{\mathrm{i}_{\mathrm{d}}(\mathrm{t})-\frac{\mathrm{v}_{\mathrm{ds}}(\mathrm{t})}{\mathrm{r}_{\mathrm{on}}}+\mathrm{i}_{\mathrm{g}}(\mathrm{t})}{\mathrm{C}_{\mathrm{gs}}}+\frac{\left(\mathrm{i}_{\mathrm{d}}(\mathrm{t})-\frac{\mathrm{v}_{\mathrm{ds}}(\mathrm{t})}{\mathrm{r}_{\mathrm{on}}}\right)}{1+\frac{\mathrm{C}_{\mathrm{ds}}}{\mathrm{C}_{\mathrm{gd}}}+\frac{\mathrm{C}_{\mathrm{ds}}}{\mathrm{C}_{\mathrm{gs}}}}}{\mathrm{C}_{\mathrm{gd}}}$

$$
\frac{d V_{g s}}{d t}=\frac{\left(i_{d}(t)-\frac{\mathrm{v}_{d s}(t)}{r_{o n}}+i_{g}(t)\right) \cdot C_{g d}+\left(i_{g}(t) \cdot C_{d s}\right)}{\mathrm{C}_{g s} \cdot C_{d s}+C_{g d} \cdot C_{g s}+C_{g d} \cdot C_{d s}}
$$

$\frac{d V_{\mathrm{ds} 2}}{\mathrm{dt}}=\frac{\left(\frac{-\mathrm{I}_{\mathrm{O}}+\mathrm{i}_{\mathrm{d}}(\mathrm{t})+\mathrm{i}_{\mathrm{g} 2}(\mathrm{t})}{\mathrm{C}_{\mathrm{gs}}}+\frac{-\mathrm{I}_{\mathrm{O}}+\mathrm{i}_{\mathrm{d}}(\mathrm{t})}{\mathrm{C}_{\mathrm{gd} 2}}\right)}{1+\frac{\mathrm{C}_{\mathrm{ds} 2}}{\mathrm{C}_{\mathrm{gd} 2}}+\frac{\mathrm{C}_{\mathrm{ds} 2}}{\mathrm{C}_{\mathrm{gs}}}}$

$\frac{d V_{\mathrm{gs} 2}}{\mathrm{dt}}=\frac{\left(-\mathrm{I}_{\mathrm{O}}+\mathrm{i}_{\mathrm{d}}(\mathrm{t})+\mathrm{i}_{\mathrm{g} 2}(\mathrm{t})\right) \cdot \mathrm{C}_{\mathrm{gd} 2}+\left(\mathrm{i}_{\mathrm{g} 2}(\mathrm{t}) \cdot \mathrm{C}_{\mathrm{ds} 2}\right)}{\mathrm{C}_{\mathrm{gs}} \cdot \mathrm{C}_{\mathrm{ds} 2}+\mathrm{C}_{\mathrm{gd} 2} \cdot \mathrm{C}_{\mathrm{gs}}+\mathrm{C}_{\mathrm{gd} 2} \cdot \mathrm{C}_{\mathrm{ds} 2}}$

As explained in the first transition, the remaining equations can be obtained using equations (8) to (17).

2.2- $\left(\mathrm{V}_{\mathrm{gs}} \geq \mathrm{V}_{\mathrm{th}}\right)$ and $\left(\mathrm{V}_{\mathrm{dsLS}}>-\mathrm{V}_{\mathrm{d}}\right)$ : The high side MOSFET behaves as a current source. The $\mathrm{V}_{\mathrm{dsLS}}$ (or $\mathrm{V}_{\mathrm{ds} 2}$ ) voltage continues decreasing.

For this subinterval, the same formulas are applied for the currents. The equations for the voltages of the high side MOSFET change by substituting the term $\mathrm{V}_{\mathrm{ds}}(\mathrm{t}) / \mathrm{r}_{\mathrm{on}}$ for $\mathrm{i}_{\text {source }}$ in equations (14) and (15).

2.3- $\left(\mathrm{V}_{\mathrm{gs}}<\mathrm{V}_{\mathrm{th}}\right)$ and while $\left(\mathrm{V}_{\mathrm{dsLS}}>-\mathrm{V}_{\mathrm{d}}\right)$ \& (transition time $<$ dead time): The gate-source voltage has decreased below the threshold voltage but there is still a $\mathrm{V}_{\mathrm{ds}}$ voltage in low side. The high side MOSFET behaves as an open circuit. 
The equations of the currents do not change and in the equations of the voltages of the high side MOSFET, the term $i_{\text {source }}$ is eliminated.

$\underline{2.4-}\left(i_{d}>0\right) \&($ transition time $<$ dead time $):$ There is low side body diode conduction and the equations are recalculated again until one of the two conditions applies.

2.5- Finally, as in the previous transition, the ringing losses that correspond to the parasitic capacitances and inductances are obtained.

3.-Final calculations: Once all the losses are calculated, the efficiency is obtained and the desired waveforms of the transitions are shown. The MOSFET voltages including the package (and the associated parasitic inductances) can be also obtained, which is useful to compare the obtained waveforms with the measurements.

\section{MODEL IMPLEMENTATION AND VALIDATION}

The model has been implemented as a function in MATLAB and has the following input data: input and output voltages and output current, switching frequency, dead times and all the parameters described in section II. With this loss model, as the equations are valid for any MOSFET that is used, the process to adapt it for a particular device is simplified, as only the analytical equations have to be obtained. The presented model allows, as said above, the calculation of the main waveforms of the converter and the breakdown losses. It can be used for a first theoretical validation, comparing the calculated waveforms to the simulation results obtained with a time domain simulator. Figure 2 shows the main waveforms of current and voltage of a highside turn on transition and in Figure 3 it is shown the good correspondence on the first 2 ns of the high side MOSFET turn-on between PSpice and the proposed model.

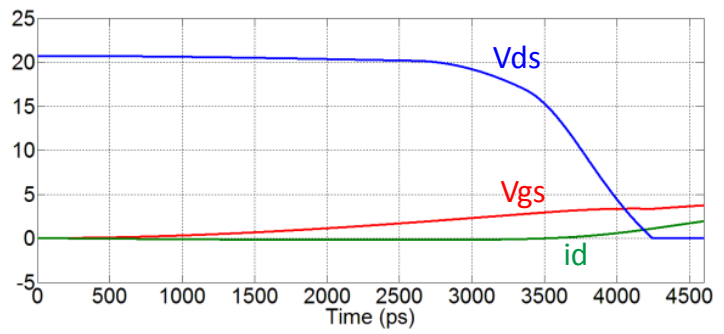

Figure 2. Waveforms of $V d s, V g s$ and id obtained with the proposed model for a high side turn-on transition

One of the characteristics of this model, compared to variable integration step of simulators as PSpice, Simplorer or Saber, is the fixed integration step. A fixed step allows avoiding a huge increase in the simulation time when the parasitic components are considered. On the other hand, a fixed integration step could cause convergence problems or less accuracy. To avoid both of them without increasing the simulation time, a small simulation step (1ps) has been chosen. As this model only needs data of one period and only calculates in detail the switching transitions to obtain the power losses, the small integration step doesn't imply a high simulation time, 2.5 (BSZ058N03), 4.5 (IRFR3707Z) and 8.5 (EPC1015) seconds experimentally on the different tests that have been done with a conventional computer.
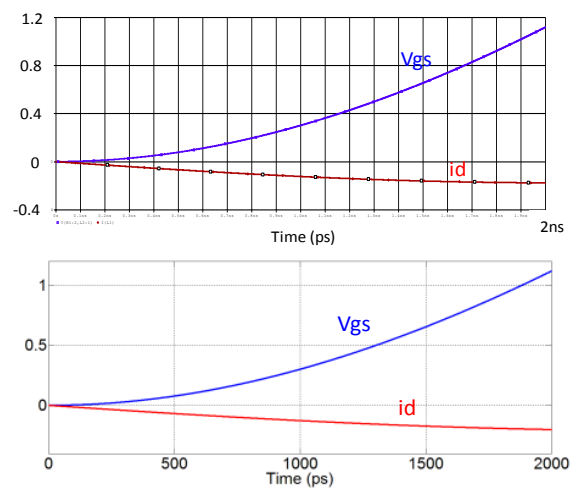

Figure 3. Waveforms of $V g s$ and id at the beginning of the high side turn-on transition (first 2ns). PSpice simulation (up) and proposed model (down)

In order to compare the calculation times with the ones obtained with a variable step simulator, LTSpice has been used. It has been developed an interface between MATLAB and LTSpice to obtain the efficiency and losses of the converter, using the MOSFET and driver models provided by the manufacturer of the devices.

Only one period is simulated to obtain the efficiency, to do a fair comparison with the presented model. The computation times obtained are of 1,9-3,6 seconds (IRFR37073Z), 0,8-1,8 seconds (BSZ058N03) and 3,515,1 seconds (EPC1015) depending on the test conditions, the selected MOSFET and the $\mathrm{L}_{\mathrm{pcb}}$, using the same computer than with the proposed model. It has been observed that $\mathrm{L}_{\mathrm{pcb}}$ limits the performance of the simulator, increasing the simulation time and the data file size, due to the decrease on the integration step on the switching transitions, so $\mathrm{L}_{\mathrm{pcb}}$ has been limited in the LTSpice simulations, specially for the BSZ058N03 and EPC1015 to obtain low computation times and data sizes that can be processed fast. It can be seen that the computation times are in the same range, with the advantage that the computation time of the proposed model does not depend so much on the test conditions.

\section{EXPERIMENTAL RESULTS}

An experimental validation of the model has been done using three different MOSFETs. Three Si devices, IRFR3707Z, BSZ058N03 and IRF8915, and one GaN device: EPC1015. Measurements have been done with the following specifications: Frequency from $500 \mathrm{kHz}$ to $4 \mathrm{MHz}$, input voltages of $20 \mathrm{~V}$ and $15 \mathrm{~V}$ and an output 
voltage of $10 \mathrm{~V}$ and $7.5 \mathrm{~V}$ respectively and an output power range from $2.5 \mathrm{~W}$ to $18 \mathrm{~W}$.

The dead times, drivers input voltages (of $5 \mathrm{~V}$ ) and currents together with input and output voltages and currents have been measured on the prototype. The parasitic inductances have been estimated with the data of the simulation model that the manufacturer of the devices supplies. For the driving stage, ISO722 isolator and EL7158 drivers have been used. The magnetic component has been designed to avoid having output current ripple.

In Figures 4 to 12 the results of the comparison can be seen. It can be appreciated that there is a good correspondence between measurements and the model for all the tests done. The highest efficiency differences are $3 \%$ at $18 \mathrm{~W}$, figure 6 , and $6 \%$ at low load in figure 8 , but considering that a $6 \%$ of error is obtained at around $2.7 \mathrm{~W}$, the error in the power losses is small $(0.43 \mathrm{~W})$.

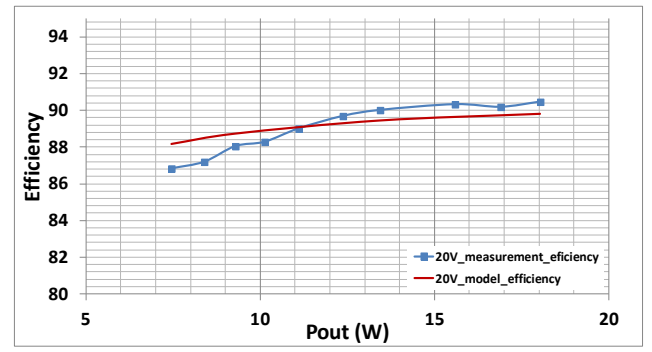

Figure 4. Measured and model efficiencies for IRFR3707Z at $2 \mathrm{MHz}$ for $20 \mathrm{~V}$ Vin and $10 \mathrm{~V}$ Vout

In figure 5 it can be seen the total predicted losses of the model compared to the measured losses, and the good correspondence between them.

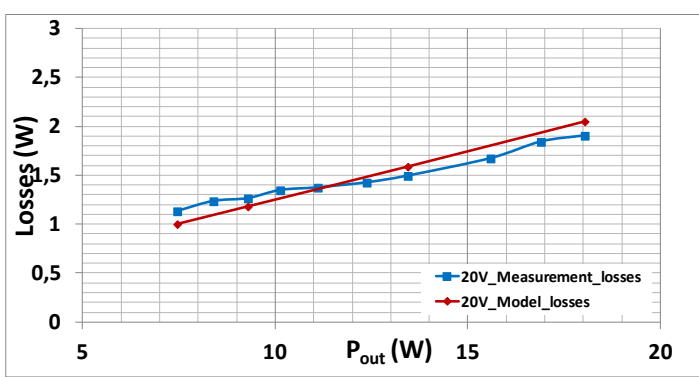

Figure 5. Measured and model losses for IRFR3707Z at $2 \mathrm{MHz}$ for $20 \mathrm{~V}$ Vin and $50 \%$ duty cycle

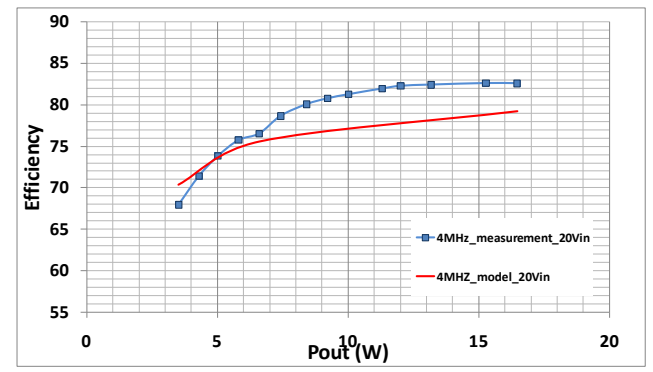

Figure 6. Measured and model efficiencies for IRFR3707Z at $4 \mathrm{MHz}$ for $20 \mathrm{~V}$ Vin and $10 \mathrm{~V}$ Vout
Although good results have been obtained, the model does not include temperature dependencies, or variation of the transconductance curve with the $\mathrm{V}_{\mathrm{ds}}$ voltage, which will be implemented in a optimization process of the model and may explain the small deviations between the model and the measurements, making the model more robust for different operating conditions.

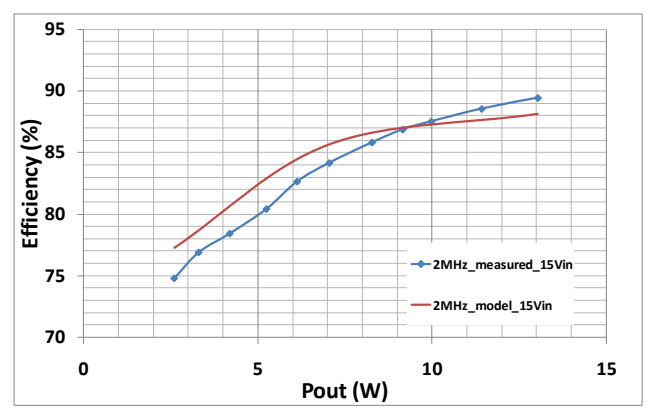

Figure 7. Measured and model efficiencies for BSZ058N03 at $2 \mathrm{MHz}$ for $15 \mathrm{~V}$ Vin and $7.5 \mathrm{~V}$ Vout

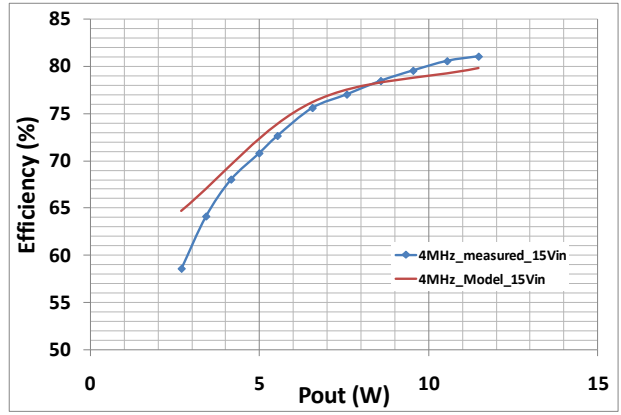

Figure 8. Measured and model efficiencies for BSZ058N03 at $4 \mathrm{MHz}$ for $15 \mathrm{~V}$ Vin and $7.5 \mathrm{~V}$ Vout

Figure 9 shows measured and model predicted losses for BSZ058N03 MOSFET between $2.7 \mathrm{~W}$ to $11.5 \mathrm{~W}$, with an input voltage of $15 \mathrm{~V}$, duty cycle of $50 \%$ and a switching frequency of $4 \mathrm{MHz}$. The prediction has a maximum error of $0.43 \mathrm{~W}$ for the lowest power in the operation range considered.

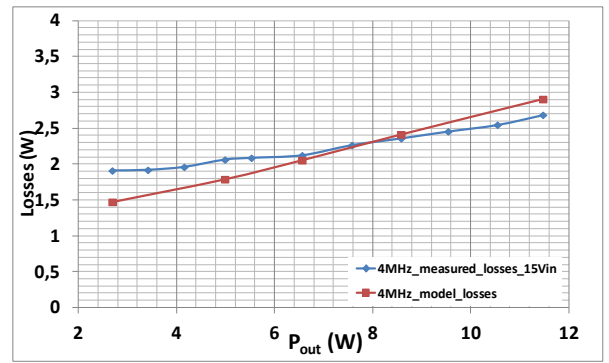

Figure 9. Measured and model losses for BSZ058N03 at $4 \mathrm{MHz}$ for $15 \mathrm{~V}$ Vin and $50 \%$ duty cycle 


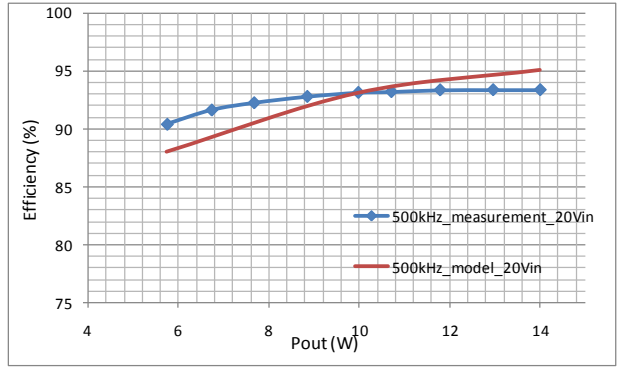

Figure 10. Measured and model efficiencies for GaN EPC1015 at $500 \mathrm{kHz} ; 20 \mathrm{~V}$ Vin $\mathcal{E} 10 \mathrm{~V}$ Vout

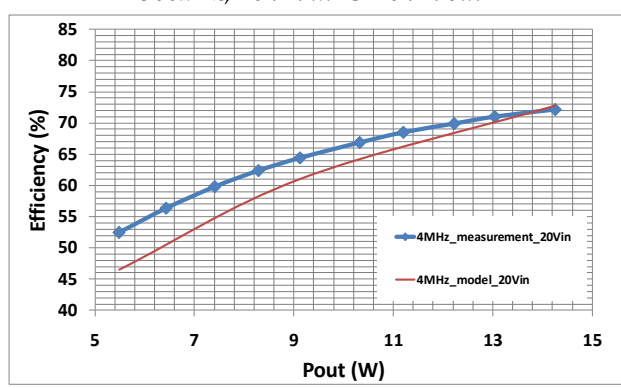

Figure 11. Measured and model efficiencies for GaN EPC1015 at $4 \mathrm{MHz} ; 20 \mathrm{~V}$ Vin $\mathcal{E} 10 \mathrm{~V}$ Vout

Additional experimental results have been obtained applying the model to a four phase synchronous buck converter, in a power range from $4 \mathrm{~W}$ to $30 \mathrm{~W}$. The switching frequency of the test has been $2.08 \mathrm{MHz}$, the input voltage of $17 \mathrm{~V}$ and the duty cycle of $50 \%$. The efficiency has been measured for a constant output current on each phase so the assumptions of the model are valid. The MOSFETs are IRF8915 and the drivers used LM27222. Figure 12 shows the good correspondence between measurements and model estimation in a wide operation range.

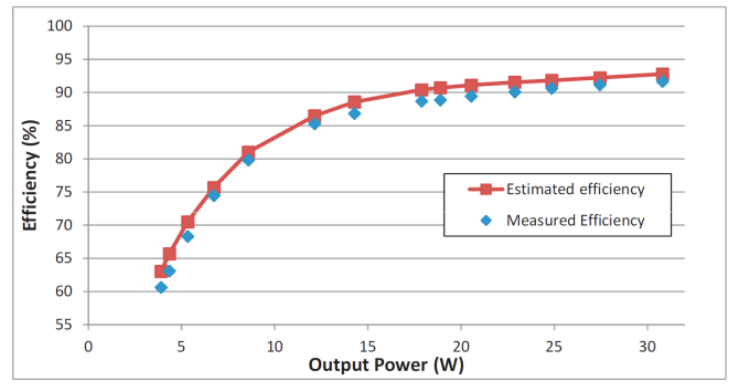

Figure 12. Measured and model efficiencies for IRF8915 at 1.8MHz; 20 Vin $\mathcal{E}$ duty cycle $=50 \%$

The proposed model allows the calculation of the breakdown losses, as shown below. It has been obtained for $7 \mathrm{~W}$ of output power and shown in Figure 13, where it can be seen that most of the losses are due to switching, gate and driving, as the assumptions of the model consider.

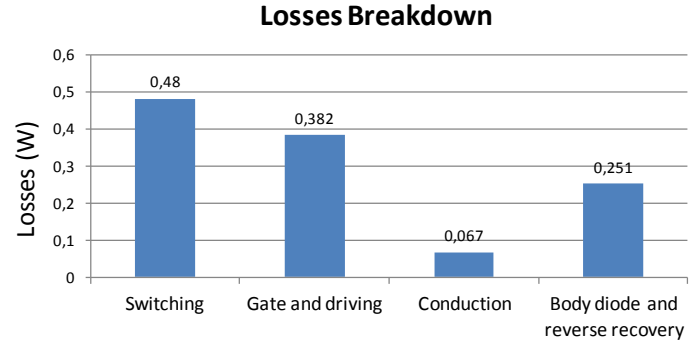

Figure 13. Losses breakdown for BSZ058N03 at $2 \mathrm{MHz}$ for $15 \mathrm{~V}$ Vin and $50 \%$ duty cycle at Pout $=7 \mathrm{~W}$

Additional future work is an extension of the switching frequency over $4 \mathrm{MHz}$ and the consideration of the magnetic losses in the model.

\section{CONCLUSION}

In this work it is presented a hybrid behavioralanalytical model of a buck converter for high frequency range operation up to $4 \mathrm{MHz}$ and low power ( $3 \mathrm{~W}$ to $18 \mathrm{~W}$ and iout $_{\max }=2.5 \mathrm{~A}$ ). The model calculates the power losses of the converter in the switching transitions using only the datasheet main parameters. The computation time of the model is below 8.5 seconds, similar to the equivalent calculation time using an SPICE based simulator which is below 15 seconds but with a higher range of variation. The good trade-off between accuracy and simulation time makes the implemented model a suitable tool for the estimation of the losses and the optimization in the design of a converter or architecture. Main waveforms of the switching transitions as well as losses breakdown are provided, using the datasheet parameters. The model behavior has been validated by simulation comparing it with PSpice. The model has been validated experimentally with four different devices, one $\mathrm{GaN}$ power transistor and three $\mathrm{Si}$ MOSFETs, obtaining a good accuracy even at high frequency and low load (maximum error of $6 \%$ or $0.43 \mathrm{~W}$ at $\mathrm{P}_{\text {out }}=2.7 \mathrm{~W}$ at high frequency and a $3 \%$ at $\left.\mathrm{P}_{\text {out }}=18 \mathrm{~W}\right)$.

\section{REFERENCES}

[1] Z. Zhang, J. Fu, Y.F. Liu, P.C. Sen, "Switching Loss Analysis Considering Parasitic Loop Inductance with Current Source Drivers for Buck Converters", IEEE Transactions on Power Electronics, Vol. 26, Issue 7, July 2011, p.1815-1819.

[2] Y. Bai, Y. Meng, A.Q. Huang, F.C. Lee, "A Novel Model for MOSFET Switching Loss Calculation", IEEE Power Electronics and Motion Control Conference, 2004, p.1669-1672.

[3] W. Eberle, Z. Zhang, Y.F. Liu, P.C. Sen, "A Practical Loss Model for Buck Voltage Regulators", IEEE Transactions on Power Electronics, Vol. 24, Issue 3, March 2009, p.700-713. 
[4] A.D. Sagneri, D.I. Anderson, D.J. Perreault, "Optimization of Transistors for Very High Frequency dc-dc Converters", IEEE Energy Conversion Congress and Exposition, September 2009, p. 1590-1602.

[5] Y. Ren, M. Xu, J. Zhou, F.C. Lee, "Analytical Loss Model of Power MOSFET", IEEE Transactions on Power Electronics", Vol. 21, Issue 2, 2006, p.310-319.

[6] M. Rodríguez, A. Rodríguez, P.F. Miaja, J. Sebastian, "Analysis of the switching process of power MOSFETs using a new analytical losses model", IEEE Energy Conversion Congress and Exposition, September 2009, p. 3790-3797.

[7] J. Wang, T. Zhao, J. Li, A.Q. Huang, R. Callanan, F. Husna, A. Agarwal, "Characterization, Modeling, and Application of $10-\mathrm{kV}$ SiC MOSFET", IEEE Transactions on Electron Devices, Vol. 55, Issue 8, July 2008, p.1798-1806.

[8] R. Pagano, "Characterization, Parameter Identification and Modeling of a New Monolithic Emitter-Switching Bipolar Transistor", IEEE Transactions on Electron Devices, Vol. 53, Issue 5, 2006, p.1235-1244.

[9] Y. Cheng, M.J. Deen, C.-H. Chen, "MOSFET Modeling for RF IC Design", IEEE Transactions on Electron Devices, Vol. 52, Issue 7, July 2005, p.1286-1303.

[10] K.A. Bowman, B.L. Austin, J.C. Eble, X. Tang, J. D. Meindl, "A Physical Alpha-Power Law MOSFET Model", IEEE Journal of Solid State Circuits, Vol. 34, Issue 10, 1999, p.1410-1414. 